\title{
Association of ACACB polymorphisms with obesity and diabetes
}

J.A. Riancho ${ }^{\text {, }, ~ L . ~ V a ́ z q u e z ~}{ }^{\text {, M.A. García-Pérez }}{ }^{\text {, J. Sainz }}$, J.M. Olmos ${ }^{\text {a }}$, J.L. Hernández ${ }^{\text {, J. J. Pérez- }}$ López $^{\mathrm{e}}$, J.A. Amado ${ }^{\mathrm{b}}$, M.T. Zarrabeitia ${ }^{\mathrm{f}}$, A. Cano ${ }^{\mathrm{g}}$, and J.C. Rodríguez-Rey

a Department of Internal Medicine, Hospital U.M. Valdecilla-IFIMAV, University of Cantabria. RETICEF. Santander, Spain.

${ }^{\mathrm{b}}$ Service of Endocrinology, Hospital U.M. Valdecilla-IFIMAV, University of Cantabria. Santander, Spain.

${ }^{\mathrm{c}}$ Department of Genetics, Fundación Investigación Hospital Clínico Valencia / INCLIVA, Universidad de Valencia, Spain

${ }^{\mathrm{d}}$ Institute of Biomedicine and Biotechnology of Cantabria (IBBTEC), CSIC-University of Cantabria. Santander, Spain.

e Department of Molecular Biology. University of Cantabria. IFIMAV, Santander, Spain

${ }^{\mathrm{f}}$ Unit of Legal Medicine. University of Cantabria. IFIMAV, Santander, Spain

${ }^{g}$ Department of Pediatrics, Obstetrics and Gynaecology, University of Valencia and University Hospital Doctor Peset. Valencia, Spain.

Correspondence and reprint requests:

José A. Riancho

Dep. Internal Medicine

Hospital U.M. Valdecilla

Avda Valdecilla s/n

39008 Santander, Spain

Fax 34942201695

Tel 34942201990

Email: rianchoj@unican.es 


\section{ABSTRACT}

Acetyl-CoA carboxylase beta, encoded by the $A C A B$ gene, plays an important role in the oxidation of fatty acids. The aim of this study was to check the hypothesis that allelic variants of $A C A C B$ influence the risk of obesity and type 2 diabetes mellitus.

Twenty five tagging single nucleotide polymorphisms (SNPs) capturing common variants of the ACACB gene were selected and analyzed in two cohorts including 1695 postmenopausal women of the general population and in 161 women with severe obesity (BMI >35). In vitro binding of transcription factors was explored by electrophoretic mobility shift assays (EMSA). T alleles at the rs2268388 locus were overrepresented in women with severe obesity (18\% vs. $10 \%$ in controls; OR 1.74 [95\% confidence interval 1.30-2.47]), which was statistically significant after multiple-test adjustment ( $\mathrm{p}=0.0004)$. Likewise, $\mathrm{T}$ alleles at the rs2268388 locus and $\mathrm{C}$ alleles at the rs2239607 locus were associated with diabetes, in the discovery as well as in the replication cohorts, even after women with severe obesity were excluded (OR 3.6 and 2.8, for TT and CC homozygotes, respectively). Allelic differences in the binding affinity for nuclear proteins were revealed in vitro by EMSA and competition experiments were consistent with the binding of glucorticoid receptor and serum response factor.

In conclusion, common polymorphisms of $A C A C B$ gene are associated with obesity and, independently, with type 2 diabetes in postmenopausal women, suggesting that the activity of acetylCoA carboxylase beta plays an important role in these disorders related to energy metabolism.

KEYWORDS: ACACB, obesity, type 2 diabetes, polymorphisms 


\section{INTRODUCTION}

Obesity and type 2 diabetes mellitus are two prevalent disorders in western countries, with a well known relationship between them [1]. Obesity constitutes a major risk factor for the development of diabetes and it is always associated with insulin resistance [2]. As many common disorders, diabetes and obesity have an important genetic component. Genome-wide studies have identified several loci related to these disorders [3-7], but those loci only explain a small fraction of the disease risk, and in many cases do not identify the causal variants [8;9], suggesting that most of the genes involved and the functional variants remain to be identified in further investigations.

It is well recognized that changes in fatty acid metabolism, particularly fatty acid oxidation, play an important role in the development of insulin resistance. Skeletal muscle from obese people is less able to oxidize fat [10], which is exacerbated in the skeletal muscle of patients with type 2 diabetes [11;12]. The metabolism of insulin-resistant skeletal muscle appears to favor fat synthesis rather than fat oxidation [13]. The imbalance between fatty acid synthesis and fatty acid oxidation further increases lipid accumulation within the cytoplasm of skeletal muscle cells, which would turn these cells even more resistant to insulin.

Acetyl-CoA carboxylase (ACAC) catalyzes the synthesis of malonyl-CoA, a key molecule in fatty acid metabolism. In humans, there are two ACAC isoforms, ACACA and ACACB, encoded by genes located in chromosomes 17 and 12, respectively. Whereas ACACA is predominantly expressed in the liver and adipose tissue, the heart and skeletal muscle are the major tissues expressing $A C A C B$. It has been suggested that ACACA plays a major role in fatty acid synthesis, whereas ACACB is preferentially involved in fatty acid oxidation [14;15]. Thus, ACACB is an appealing candidate gene for obesity and diabetes, which are characterized by an impaired fat oxidation. Therefore, the aim of this study was to test the hypothesis that allelic variants of the ACACB gene are associated with obesity and/or diabetes. 


\section{MATERIALS AND METHODS}

\subsection{Study subjects and genotyping}

The discovery cohort included 972 Caucasian postmenopausal women from the general population (mean age 66; range 47-88) taking part in epidemiologic studies about mineral metabolism and cardiovascular risk [16;17]. All were living in Cantabria, a small region in Northern Spain and provided informed consent. Women with non-Spanish ancestors were excluded.

The severe obesity group included 161 female patients, 50-81 years of age, from the obesity outpatient clinic, with BMI above $35 \mathrm{~kg} / \mathrm{m}^{2}$. Patients with metabolic disorders causing secondary obesity were excluded. BMI varied between 35.1 and $62.4 \mathrm{~kg} / \mathrm{m}^{2}$ (table 1).

We selected tagging SNPs covering the common variation of the ACACB gene with Tagger software using the following parameters: minor allele frequency (MAF) of $10 \%$, capture threshold of $r^{2}>=$ 0.8, and a maximum tagging distance of $200 \mathrm{~kb}$. For comparison purposes, the rs1121980 polymorphism of the FTO gene was also studied, as it has been associated with obesity in several studies [18]. DNA was isolated from peripheral blood by using standard procedures and quantified with the Qubit system (Invitrogen). SNPs were analysed by iPlex technology on a Mass-Array platform (Sequenom, Germany).

SNPs showing phenotypic associations in the discovery cohorts were also analyzed in the Valencia cohort. This replication cohort included 723 Caucasian postmenopausal women aged 45-82 years attending a menopause clinic and living in Valencia, a Mediterranean region in Eastern Spain.

Patients with type 2 diabetes were identified according to the 2003 ADA criteria $\left[{ }^{19}\right]$. Patients with type 1 diabetes or secondary diabetes were not included in the study cohorts.

\subsection{In silico analysis of transcription factor binding}

For investigating if the nucleotide changes might result in changes in the binding of transcription factors, we carried out an in silico analysis of the surrounding sequence (plus and minus 30 nucleotides), by using MattInspector and MAPPER search tools [ $\left.{ }^{20 ; 21}\right]$. 


\subsection{Electrophoretic mobility shift assays}

Nuclear extracts were prepared from sub-confluent HepG2 cell cultures as previously reported $\left[{ }^{22}\right]$. For rs2268388, 27-nt long double-stranded oligonucleotides, with the sequence GGCAGAGAACACTC[C/T]GTTTCCTGCCCA were used. The rs22399607 specific oligonucleotide had the sequence GGCCCCTGATA[C/T]GTTAGGCTATAA. They were labeled in 5'with IRDye ${ }^{\circledR} 680$ (Tecknochrom). The gel bands were analyzed in an ODYSSEY infrared imaging system (Li-Cor Biosciences, Lincoln, NE). The relative affinity of each allele was analysed by competing it with increasing amounts of the unlabelled allele which had shown a stronger binding. The bands were quantified and the affinities were calculated by representing the inverse of band intensity versus the excess of unlabelled oligonucleotide. A higher slope indicated lower oligonucleotide-protein affinity. Competition experiments were carried out using oligonucleotides containing the consensus binding sequences for the glucocorticoid receptor (ATTACTAGAACATCCTGTACAGTCGAC) or the serum response factor (TACACAGGATGTCCATATTAGGACATC) $\left[{ }^{23 ; 24}\right]$.

\subsection{Statistical analysis}

The HWE was tested with Plink software. Haplotypic blocks were constructed with Haploview, using the Gabriel method $\left[{ }^{25}\right]$. The associations of alleles and genotypes with BMI, obesity and diabetes were tested with Plink $\left[{ }^{26}\right]$. Since BMI distribution was skewed, the statistical analysis was performed with log-transformed values. Haplotype analyses was performed using a 2- or 3-SNP sliding window. Power estimates were obtained with Quanto software (available at http://hydra.usc.edu/gxe/). The power of the study to detect a locus associated with disease in the discovery cohort was $68 \%$ and $99 \%$, for odds ratio (OR) of 1.5 and 2, respectively, if the minor allele frequency was higher than $10 \%$. Similarly, it had $87 \%$ and $99 \%$ power to detect a locus explaining at least $1 \%$ and $2 \%$, respectively, of the variance of a quantitative trait such as BMI. The 
multiple test threshold for significance was estimated with the method of Li and Ji, as implemented in the SnpSpd web tool $\left[{ }^{27}\right]$, which takes into consideration the linkage disequilibrium between loci. The estimated number of independent tests was 14, resulting in a multiple test-adjusted significance threshold of 0.0037 . To obtain a combined estimate of the genotype-phenotype associations in the discovery and replication cohorts, the Maentel-Haenszel adjusted ORs were calculated using Epidat software (available at http://www.sergas.es/MostrarContidos_N3_T01.aspx?IdPaxina=62713).

\section{RESULTS}

\subsection{Association of ACACB polymorphisms with adiposity}

The characteristics of women studied are shown in table 1.

One of the 26 SNPs selected was excluded because of genotyping technical problems (rs4766587); 3 other SNPs were excluded because questionable HWE, with uncorrected p-values <0.05 (table 2). The haplotypic block structure is shown in figure 1.

The single locus analysis did not reveal significant associations of ACACB polymorphisms with BMI in the general population. Likewise, no association was found between the FTO polymorphism and BMI. However, in the whole study group (general population and women with severe obesity together), rs2268388 genotypes were significantly associated with BMI ( $p=0.0043)$, almost reaching the 0.0037 threshold for significance after correction for multiple tests. $T$ alleles were associated with higher BMI. The mean BMI values in women with TT, TC and CC genotypes were 34.1 \pm 8.4 , $32.0 \pm 11.9$ and $30.4 \pm 7.2 \mathrm{~kg} / \mathrm{m}^{2}$, respectively. The haplotypic analysis confirmed the results but did not increase the strength of association (not shown), and the haplotypic conditional analysis revealed that rs2268388 was the only independent contributor to the association. There were marked differences between the genotype frequencies in the general population and in women with severe obesity: $T$ alleles were overrepresented in the severe obesity population $(18 \%$, versus $10 \%$ in 
controls; OR 1.74 [95\% confidence interval 1.30-2,47], $\mathrm{p}=0.0004$ ) (table 3). The significance of the association was below the multiple test adjusted threshold and the association was quantitatively similar to that found with the rs1121980 polymorphism of the FTO gene (OR 1.56 [95\% CI 1.231.97], $\mathrm{p}=0.00026$ ) (figure 2). Similar results were found in the haplotypic analysis (not shown).

In the Valencia cohort, the rs2268388 was not associated with BMI, thus confirming the lack of association between BMI and ACACB allelic variants in the general population.

\subsection{Association of ACACB polymorphisms with type 2 diabetes}

Since obesity is a well-known factor associated with type 2 diabetes, we analyzed the association of ACACB polymorphisms with diabetes mellitus after excluding women with marked elevations of BMI (ie, BMI>35).

We found several polymorphisms within a $14 \mathrm{~kb}$ distance of rs2268388 associated with diabetes (table 4). The rs2239607 polymorphism, located $3.5 \mathrm{~kb}$ downstream of rs2268388, showed the strongest association, almost reaching the multiple test-adjusted significance. $C$ alleles were associated with higher risk of diabetes. The genotypes frequencies were: $C C 7.9 \%, C T 42.1 \%$ and TT 50.0\% in diabetic patients; and 3.6\%, 32.1\% and 64.3\%, respectively, in non-diabetic women. Similar results were obtained when BMI was included as a covariate (table 4).

Two polymorphisms associated with type 2 diabetes in the discovery cohort were also analyzed in the Valencia cohort, rs2268388 and rs2239607. In this cohort both polymorphisms also showed a significant association with type 2 diabetes, that appeared to fit better a recessive genetic model (pvalues 0.005 and 0.021 , respectively). The risk alleles were the same in both populations (Cantabria and Valencia): $T$ alleles at the rs2268388 locus and $C$ alleles at rs2239607 locus. Thus, when the results of both cohorts were combined, in comparison with the most common $C C$ genotype at rs2268388, OR for the $T T$ genotype was 3.6, whereas in comparison with the most common $T T$ genotype at the rs2239607 locus, OR for CC genotype was and 2.8 (95\% CI 1.4-5.6) (table 5). 


\subsection{Functional analysis of rs2268388 and rs2239607}

The ability of different alleles to bind transcription factors was explored by EMSA. The experiments showed that the T-allele oligonucleotide of rs2268388 had higher binding than the C-allele, a result confirmed in competition experiments (figure 3). Similar EMSA experiments were carried out with oligonucleotides specific for the two alleles of the rs2239607 polymorphism. As shown in the figure 3, there were allelic differences in nuclear protein binding, with stronger binding to the T-allele oligonucleotides.

The in silico analysis of transcription factor binding sites suggested that the nucleotide change altered the affinity of the glucocorticoid receptor (GR) for the sequence including the rs2239607 polymorphism, as well as the affinity of the Serum Response Factor (SRF), a transcription factor that has been associated with insulin response, for the DNA region containing the rs2239607 polymorphism. Indeed, competition experiments with a 20-fold excess of an unlabeled oligonucleotide known to bind GR displaced the proteins from the labeled rs226388 oligonucleotide, suggesting that GR contributes to the formation of the retarded protein-DNA complex (figure 4). On the other hand, competition with an unlabeled oligonucleotide containing the SRF binding site completely displaced the proteins from the labeled rs2239607 oligonucleotide, indicating the presence of SRF in the complex (figure 4).

\section{DISCUSSION}

$A C A C B$ encodes one of the major forms of the enzyme catalyzing the synthesis of malonyl-CoA. Malonyl-CoA serves both as an intermediate in fatty acid synthesis and as an allosteric inhibitor of carnitine palmitoyltranferase 1(CPT1) which regulates the transfer of long-chain fatty acyl-CoAs from the cytosol into the mitochondria. The two isoforms of ACAC, ACACA and ACACB, have a high degree of sequence identity, the major difference being in the N- terminal domain of ACACB, which is known to help the binding to the mitochondrial membrane and regulates local malonyl-CoA 
levels, CPT1 activity and consequently fatty acid oxidation[10]. The different ability of ACACA and ACACB to bind to the mitochondrial membrane, together with their tissue expression patterns, suggest that the fate of the malonyl-CoA synthesized is different: while ACACA is preferentially involved in fatty acids synthesis, ACACB controls fatty acid oxidation. In agreement with this, ACACA knock out mice, with a markedly impaired ability to synthesize fatty acids, die before birth. The effect of ACACB suppression in mice is controversial. Initial reports suggested that null mice are leaner than wild type, mainly due to an increased rate of fat oxidation in both heart and skeletal muscle $\left[{ }^{14 ; 28}\right]$. However, those observations have been questioned $\left[{ }^{29}\right]$.

Further studies are needed to elucidate the actual role of both ACAC forms in lipid metabolism in physiological and pathological conditions in different tissues. Nevertheless, the fact that ACACB synthesizes the malonyl-CoA used for CPTI inhibition points it as an attractive candidate gene for disorders of energy metabolism, such as obesity and diabetes, which are characterized by an impaired fat oxidation. As of July 2011, the Catalog of Genome-Wide Association Studies (www.genome.gov/gwastudies) includes 40 studies on body mass, diabetes or type 2 diabetes. These studies report 192 SNPs with P values $<10^{-5}$ and 147 genes. ACACB, which locates at $12 \mathrm{q} 24.11$, is not reported and the closest gene to ACACB among those reported is HNF1A, located at 12q24.31 or approximately 11.8 Mb in the NCBI36/hg18 genome assembly. However, it cannot exclude an influence of ACACB variants on the risk of suffering disorders of energy metabolism. Sample size, inclusion of heterogeneous groups of patients and other factors may limit the power of GWAS to identify some genes truly related to the phenotype studied. In fact, results of other investigators suggested that ACACB variants could be associated with the metabolic syndrome $\left[{ }^{30}\right]$ or with the risk of diabetic nephropathy [ $\left.{ }^{31 ; 32}\right]$. In a large-scale genotyping analysis of patients with type 2 diabetes Maeda et al. identified found SNP rs2268388 associated with proteinuria in Japanese patients and with end-stage renal diseases in European Americans. As in our study, $T$ was the risk allele. In experiments with reporter vectors they found that the risk allele had higher enhancer 
activity than the alternative allele in cultured renal cells $\left[{ }^{31}\right]$ This same allele has been associated by Tang et al with the risk of nephropathy in Chinese diabetic patients $\left[{ }^{32}\right]$. Those studies suggest that that $A C A C B$ gene, and specifically rs2268388, influences the susceptibility to diabetic nephropathy and implicate fatty acid oxidation in the pathogenesis of this disorder. Our own results suggest that some allelic variants of $A C A C B$, including those of the rs2268388 polymorphism, are indeed associated with severe obesity and, independently, with type 2 diabetes.

We found that $T$ alleles at the rs2268388 locus were much more frequent in women with severe obesity than in controls. Interestingly enough, the strength of association was similar to that of FTO, a well-recognized candidate gene for obesity $\left[{ }^{18 ; 33-35}\right]$. However, we did not find a statistically significant association of $A C A C B$ alleles with BMI in the general population. These results suggest that $A C A C B$ variants have a stronger influence on extreme BMI than on the variation of BMI within the normal or moderately increased range. The explanation for this observation is unclear, but it is tempting to speculate that diet and other acquired factors may play a predominant role in overweight and mild obesity, whereas genetic factors may be the most important in severe obesity. On the other hand, these results reflect the "power of extremes", this is, the interest of studying extreme phenotypes when exploring the involvement of genes in common disorders $\left[{ }^{36}\right]$.

$A C A C B$ polymorphisms were also associated with type 2 diabetes mellitus. In this analysis we excluded women with severe obesity, who have a very high frequency of diabetes. The results were replicated in two independent cohorts and confirmed the association of ACACB variants with disorders of energy metabolism. The association of $A C A C B$ with diabetes is not surprising as an association of this gene with the metabolic syndrome has been reported recently $\left[{ }^{37}\right]$. The results presented here indicate that there is an imperfect overlapping of the SNPs associated with severe obesity and those associated with diabetes. This is an intriguing result because the major SNPs associated with either condition are only $3.0 \mathrm{~kb}$ apart. It is possible to speculate that changes in the polymorphic loci studied, or in the surrounding regions, produce subtle functional changes that in 
turn modify ACACB activity. Since SNPs associated with obesity or diabetes are located in introns, the most plausible explanation is that their alleles influence ACACB gene expression. Both obesity and diabetes are disorders with a large environmental influence. Therefore, the lack of complete overlapping between the loci associated with obesity and diabetes might reflect the existence of regulatory elements responding to different environmental factors and causing subtle changes in gene expression. Interestingly, the reported association of $A C A C B$ with the metabolic syndrome seems to be modulated by dietary fat $\left[{ }^{37}\right]$.

Our study has some limitations. We only studied Caucasian women. Therefore, it is unclear if these results can be extrapolated to men or women with other ethnic background. On the other hand, we have limited information about dietary habits and physical activity. Therefore, we could not explore the potential interactions between those acquired factors and genetic factors, which clearly is an important subject for future studies. Candidate gene studies can have false positive results, due to population stratification and other causes of bias. We used various strategies to diminish this risk and support the validity of the associations. First, we studied women from a limited geographic area and excluded those with non-Spanish ancestors. Second, we used a multiple test-corrected threshold for statistical significance to diminish the type I error risk related to the multiple SNPs analyzed. Furthermore, we replicated the association of $A C A C B$ polymorphisms with type 2 diabetes in a different cohort of women. Unfortunately, a group of women with severe obesity was not available for replication. On the other hand, the association between ACACB polymorphisms, obesity and diabetes is plausible from a biological point of view, as discussed above. In multivariate analyses the association between $A C A C B$ polymorphisms and type 2 diabetes was independent of BMI. However, there were very few patients with diabetes and $\mathrm{BMI}<25$. Therefore, we could not make a BMI-stratified analysis to compare the strength of association between $A C A C B$ variants and diabetes in overweight and lean women. 
We also explored the potential functional consequences of the allelic changes in vitro. Although the study of the regulatory properties of the regions surrounding SNPs is a complex issue, we used an indirect approach by analyzing the changes in the protein binding properties of those DNA regions. Our in vitro studies demonstrated a differential binding of nuclear factors to the alleles of the major loci associated with obesity and diabetes. These results are in line with those by Maeda et al $\left[{ }^{31}\right]$ and suggested a functional role of those polymorphisms. However, as an alternative explanation, the association between $A C A C B$ variants and obesity/diabetes could be actually due to other true regulatory loci in linkage disequilibrium with those analyzed in the present study. Whether the polymorphisms are located in real regulatory elements or not will require further research. Nevertheless, bioinformatics analyses and EMSA with competing oligonucleotides suggested that the glucocorticoid receptor and SRF bound to the polymorphic regions of the ACACB gene. These results are quite interesting, in view of the well-recognized metabolic effects of glucocorticoids, and the recently reported influence of SRF on insulin resistance $\left[{ }^{38}\right]$.

In summary, our results show that allelic variants of the $A C A C B$ gene are associated with severe obesity and with type 2 diabetes mellitus, thus adding new information to the complex genetic nature of those disorders. Further studies are required to elucidate the molecular mechanisms involved and to delineate the interactions between environmental factors and gene variants. 


\section{ACKNOWLEDGEMENTS}

Supported in part by grants from the Instituto de Salud Carlos III-FIS (PI08/0183, PS09/01687, PS09/00184, PS09/00962). JPL has a fellowship from IFIMAV (Instituto de Formación e Investigación Marqués de Valdecilla). The funding sources had no role in study design, analysis and interpretation of data, writing of the report or the decision to submit the paper for publication.

We acknowledge the excellent technical assistance of Carolina Sañudo, Verónica Mijares and Jana Arozamena. 


\section{TABLES}

Table 1. Characteristics of women studied.

\begin{tabular}{lccc}
\hline & $\begin{array}{c}\text { Discovery cohort } \\
(\mathrm{n}=972)\end{array}$ & $\begin{array}{c}\text { Morbid obesity } \\
(\mathrm{n}=161)\end{array}$ & $\begin{array}{c}\text { Replication cohort } \\
(\mathrm{n}=723)\end{array}$ \\
\hline Age, yr & $66 \pm 8$ & $59 \pm 8$ & $57 \pm 6$ \\
Height, cm & $155 \pm 6$ & $155 \pm 111$ & $157 \pm 6$ \\
Weight, kg & $68 \pm 11$ & $108 \pm 17$ & $66 \pm 11$ \\
BMI, kg/m2 & $28.3 \pm 4.4$ & $44.7 \pm 5.8$ & $26.7 \pm 4.3$ \\
Diabetes, \% & 9.9 & 39.8 & 11.5 \\
\hline
\end{tabular}


Table 2. SNPs analyzed.

\begin{tabular}{|c|c|c|c|c|c|c|}
\hline SNP & $\begin{array}{c}\text { Chromosome } \\
\text { location }\end{array}$ & $\begin{array}{c}\text { Relative location } \\
\text { (Hg18) }\end{array}$ & Allele 1 & Allele 2 & MAF & $\begin{array}{c}\text { p-value } \\
\text { HWE }\end{array}$ \\
\hline rs7969109 & 108054040 & upstream & $\mathrm{C}$ & $\mathrm{T}$ & 0.189 & 0.44 \\
\hline rs1654875 & 108057512 & upstream & A & $\mathrm{T}$ & 0.242 & 0.74 \\
\hline rs3858707 & 108065876 & intron & A & G & 0.367 & 0.52 \\
\hline rs2300460 & 108070434 & intron & $\mathrm{C}$ & $\mathrm{T}$ & 0.169 & 0.46 \\
\hline rs2268390 & 108119660 & intron & $\mathrm{A}$ & $\mathrm{G}$ & 0.193 & 0.34 \\
\hline rs7976245 & 108125545 & intron & A & $\mathrm{G}$ & 0.385 & 0.62 \\
\hline rs4766455 & 108125961 & intron & $\mathrm{C}$ & G & 0.161 & 0.91 \\
\hline rs4766564 & 108126216 & intron & $\mathrm{T}$ & $\mathrm{A}$ & 0.431 & 0.47 \\
\hline rs4766565 & 108126361 & intron & A & $\mathrm{G}$ & 0.161 & 1.00 \\
\hline rs2268388 & 108128028 & intron & $\mathrm{T}$ & $\mathrm{C}$ & 0.117 & 0.04 \\
\hline rs2268387 & 108128078 & intron & $\mathrm{C}$ & $\mathrm{T}$ & 0.458 & 0.86 \\
\hline rs12818490 & 108128830 & intron & A & $\mathrm{G}$ & 0.275 & 0.00003 \\
\hline rs2239608 & 108131105 & intron & G & $\mathrm{T}$ & 0.317 & 0.95 \\
\hline rs2239607 & 108131663 & intron & $\mathrm{C}$ & $\mathrm{T}$ & 0.203 & 0.47 \\
\hline rs11613533 & 108135607 & intron & $\mathrm{T}$ & $\mathrm{C}$ & 0.143 & 0.40 \\
\hline rs2300452 & 108142453 & intron & $\mathrm{T}$ & $\mathrm{C}$ & 0.203 & 0.41 \\
\hline rs4766584 & 108147964 & intron & G & A & 0.318 & 0.79 \\
\hline rs3742026 & 108155040 & intron & G & $\mathrm{C}$ & 0.366 & 0.44 \\
\hline rs7963249 & 108156432 & intron & A & $\mathrm{G}$ & 0.251 & 0.00019 \\
\hline rs2241220 & 108159412 & coding-synon & $\mathrm{T}$ & $\mathrm{C}$ & 0.148 & 0.82 \\
\hline rs2160602 & 108164386 & intron & $\mathrm{T}$ & $\mathrm{A}$ & 0.393 & 0.03 \\
\hline rs2284689 & 108169928 & intron & $\mathrm{T}$ & $\mathrm{C}$ & 0.168 & 0.07 \\
\hline rs2268385 & 108173429 & intron & $\mathrm{C}$ & G & 0.204 & 0.86 \\
\hline rs2268384 & 108173776 & intron & $\mathrm{G}$ & A & 0.470 & 0.51 \\
\hline rs3742023 & 108178365 & coding-synon & A & $\mathrm{G}$ & 0.417 & 0.71 \\
\hline
\end{tabular}


Table 3. Allele and genotype frequencies of the rs2268388 polymorphism in women with morbid obesity and controls (general population). The odds ratio and the $95 \%$ confidence intervals are also shown.

\begin{tabular}{lccccc}
\hline & $C$ & $T$ & $C C$ & $T C$ & $T T$ \\
& $\%$ & $\%$ & $\mathrm{n}(\%)$ & $\mathrm{n}(\%)$ & $\mathrm{n}(\%)$ \\
\hline Cases & 82.3 & 17.7 & $113(70.2)$ & $39(24.2)$ & $9(5.6)$ \\
Controls & 89.3 & 10.7 & $778(80.0)$ & $180(18.5)$ & $14(1.4)$ \\
OR & - & - & 1 & 1.49 & 4.43 \\
& & & (reference) & $(1.00-2.22)$ & $(1.87-10.46)$ \\
\hline
\end{tabular}


Table 4. Allele frequencies of SNPs associated with type 2 diabetes in the discovery cohort. Unadjusted and BMI-adjusted odds ratio (and 95\% confidence intervals) and the corresponding pvalues are also shown.

\begin{tabular}{|c|c|c|c|c|c|c|c|}
\hline SNP & $\begin{array}{l}\text { Minor } \\
\text { allele }\end{array}$ & $\begin{array}{c}\text { Frequency } \\
\text { in cases }\end{array}$ & $\begin{array}{l}\text { Frequency } \\
\text { in controls }\end{array}$ & OR & $\mathrm{p}$ & $\begin{array}{c}\text { Adjusted } \\
\text { OR }\end{array}$ & $\mathrm{p}$ \\
\hline rs2268388 & $T$ & 0.153 & 0.102 & $\begin{array}{c}1.60 \\
(0.99-2.57)\end{array}$ & 0.049 & $\begin{array}{c}1.58 \\
(0.99-2.52)\end{array}$ & 0.056 \\
\hline rs12818490 & $A$ & 0.347 & 0.264 & $\begin{array}{c}1.48 \\
(1.04-2.11)\end{array}$ & 0.028 & $\begin{array}{c}1.42 \\
(1.01-1.98)\end{array}$ & 0.041 \\
\hline rs2239607 & C & 0.289 & 0.194 & $\begin{array}{c}1.69 \\
(1.16-2.45)\end{array}$ & 0.005 & $\begin{array}{c}1.70 \\
(1.16-2.50)\end{array}$ & 0.006 \\
\hline rs2300452 & $T$ & 0.276 & 0.197 & $\begin{array}{c}1.56 \\
(1.07-2.27)\end{array}$ & 0.021 & $\begin{array}{c}1.54 \\
(1.05-2.26)\end{array}$ & 0.026 \\
\hline rs2160602 & $T$ & 0.316 & 0.404 & $\begin{array}{c}0.68 \\
(0.48-0.97)\end{array}$ & 0.034 & $\begin{array}{c}0.69 \\
(0.49-0.98)\end{array}$ & 0.039 \\
\hline
\end{tabular}


Table 5. Genotype frequencies in patients with type 2 diabetes and controls in the discovery and replication cohorts. The Mantel-Haenszel adjusted odds ratio (OR), considering the most frequent genotypes as the reference, and the p-values for trend are also shown.

\begin{tabular}{rcccccc}
\hline & \multicolumn{2}{c}{ Discovery cohort } & \multicolumn{2}{c}{ Replication cohort } & $\begin{array}{c}\text { Combined } \\
\text { OR }\end{array}$ & p \\
\hline & Cases, \% & Controls, \% & Cases, \% & Controls, \% & & \\
\hline rs2268388 & & & & & & \\
TT & 2.7 & 1.4 & 4.3 & 0.7 & $3.6(1.3-10.2)$ & 0.012 \\
TC & 25.3 & 17.5 & 22.9 & 20.9 & $1.4(0.9-2.1)$ & \\
CC & 72.0 & 81.1 & 72.8 & 78.4 & 1 & \\
\hline rs2239607 & & & & & $2.9(1.5-5.6)$ & 0.018 \\
CC & 8.9 & 3.4 & 8.3 & 3.1 & $1.2(0.8-1.7)$ & \\
CT & 34.3 & 32.2 & 26.4 & 33.5 & 1 & \\
TT & 56.8 & 64.4 & 65.3 & 63.5 & & \\
\hline
\end{tabular}




\section{FIGURE LEGENDS}

Figure 1. Linkage disequilibrium map and haplotypic blocks.

Figure 2. Association between ACACB polymorphisms and severe obesity in the discovery cohort. The association of the FTO polymorphism is also shown for comparison.

Figure 3. Electrophoretic shift mobility assays (EMSA) with oligonucleotide probes for the regions of polymorphisms rs2268388 (A) and rs2239607 (B). The binding of nuclear proteins to fluorochrome-labelled probes with the sequence of each allele, in the absence or presence of excess unlabelled nucleotide is shown. Control lanes in absence of nuclear extracts are also shown. The graphs represent the inverse of band intensity versus unlabelled competitor; thus, the slope is inversely related to the oligonucleotide-protein binding affinity.

Figure 4. EMSA with a labelled probe for the rs2268388 region and competition with a 20-fold excess of an unlabelled oligonucleotide containing the GR binding site (left) or with a labeled probe for the rs2239607 region and competition with an unlabelled oligonucleotide containing the SRF binding site (right). NE, no protein extract; E, protein extract from HepG2 cultures was added to the mix; X20, a 20-fold excess of an GR or SRF binding site oligonucleotide added to the reaction. The retarded band is pointed with an arrow. 


\section{REFERENCES}

[1] N.T.Nguyen, X.M.Nguyen, J.Lane, P.Wang. Relationship between obesity and diabetes in a US adult population: findings from the National Health and Nutrition Examination Survey, 1999-2006, Obes.Surg., 21, (2011) 351-355.

[2] R.A.DeFronzo, E.Ferrannini. Insulin resistance. A multifaceted syndrome responsible for NIDDM, obesity, hypertension, dyslipidemia, and atherosclerotic cardiovascular disease, Diabetes Care, 14, (1991) 173-194.

[3] R.Saxena, B.F.Voight, V.Lyssenko, N.P.Burtt, P.I.de Bakker, H.Chen, J.J.Roix, S.Kathiresan, J.N.Hirschhorn, M.J.Daly, T.E.Hughes, L.Groop, D.Altshuler, P.Almgren, J.C.Florez, J.Meyer, K.Ardlie, B.K.Bengtsson, B.Isomaa, G.Lettre, U.Lindblad, H.N.Lyon, O.Melander, C.Newton-Cheh, P.Nilsson, M.Orho-Melander, L.Rastam, E.K.Speliotes, M.R.Taskinen, T.Tuomi, C.Guiducci, A.Berglund, J.Carlson, L.Gianniny, R.Hackett, L.Hall, J.Holmkvist, E.Laurila, M.Sjogren, M.Sterner, A.Surti, M.Svensson, M.Svensson, R.Tewhey, B.Blumenstiel, M.Parkin, M.Defelice, R.Barry, W.Brodeur, J.Camarata, N.Chia, M.Fava, J.Gibbons, B.Handsaker, C.Healy, K.Nguyen, C.Gates, C.Sougnez, D.Gage, M.Nizzari, S.B.Gabriel, G.W.Chirn, Q.Ma, H.Parikh, D.Richardson, D.Ricke, S.Purcell. Genome-wide association analysis identifies loci for type 2 diabetes and triglyceride levels, Science, 316, (2007) 1331-1336.

[4] L.J.Scott, K.L.Mohlke, L.L.Bonnycastle, C.J.Willer, Y.Li, W.L.Duren, M.R.Erdos, H.M.Stringham, P.S.Chines, A.U.Jackson, L.Prokunina-Olsson, C.J.Ding, A.J.Swift, N.Narisu, T.Hu, R.Pruim, R.Xiao, X.Y.Li, K.N.Conneely, N.L.Riebow, A.G.Sprau, M.Tong, P.P.White, K.N.Hetrick, M.W.Barnhart, C.W.Bark, J.L.Goldstein, L.Watkins, F.Xiang, J.Saramies, T.A.Buchanan, R.M.Watanabe, T.T.Valle, L.Kinnunen, G.R.Abecasis, E.W.Pugh, K.F.Doheny, R.N.Bergman, J.Tuomilehto, F.S.Collins, M.Boehnke. A genomewide association study of type 2 diabetes in Finns detects multiple susceptibility variants, Science, 316, (2007) 1341-1345.

[5] R.Sladek, G.Rocheleau, J.Rung, C.Dina, L.Shen, D.Serre, P.Boutin, D.Vincent, A.Belisle, S.Hadjadj, B.Balkau, B.Heude, G.Charpentier, T.J.Hudson, A.Montpetit, A.V.Pshezhetsky, M.Prentki, B.I.Posner, D.J.Balding, D.Meyre, C.Polychronakos, P.Froguel. A genome-wide association study identifies novel risk loci for type 2 diabetes, Nature, 445, (2007) 881-885.

[6] E.Zeggini, L.J.Scott, R.Saxena, B.F.Voight, J.L.Marchini, T.Hu, P.I.de Bakker, G.R.Abecasis, P.Almgren, G.Andersen, K.Ardlie, K.B.Bostrom, R.N.Bergman, L.L.Bonnycastle, K.Borch-Johnsen, N.P.Burtt, H.Chen, P.S.Chines, M.J.Daly, P.Deodhar, C.J.Ding, A.S.Doney, W.L.Duren, K.S.Elliott, M.R.Erdos, T.M.Frayling, R.M.Freathy, L.Gianniny, H.Grallert, N.Grarup, C.J.Groves, C.Guiducci, T.Hansen, C.Herder, G.A.Hitman, T.E.Hughes, B.Isomaa, A.U.Jackson, T.Jorgensen, A.Kong, K.Kubalanza, F.G.Kuruvilla, J.Kuusisto, C.Langenberg, H.Lango, T.Lauritzen, Y.Li, C.M.Lindgren, V.Lyssenko, A.F.Marvelle, C.Meisinger, K.Midthjell, K.L.Mohlke, M.A.Morken, A.D.Morris, N.Narisu, P.Nilsson, K.R.Owen, C.N.Palmer, F.Payne, J.R.Perry, E.Pettersen, C.Platou, I.Prokopenko, L.Qi, L.Qin, N.W.Rayner, M.Rees, J.J.Roix, A.Sandbaek, B.Shields, M.Sjogren, V.Steinthorsdottir, H.M.Stringham, A.J.Swift, G.Thorleifsson, 
U.Thorsteinsdottir, N.J.Timpson, T.Tuomi, J.Tuomilehto, M.Walker, R.M.Watanabe, M.N.Weedon, C.J.Willer, T.Illig, K.Hveem, F.B.Hu, M.Laakso, K.Stefansson, O.Pedersen, N.J.Wareham, I.Barroso, A.T.Hattersley, F.S.Collins, L.Groop, M.I.McCarthy, M.Boehnke, D.Altshuler. Meta-analysis of genome-wide association data and large-scale replication identifies additional susceptibility loci for type 2 diabetes, Nat.Genet., 40, (2008) 638-645.

[7] E.Zeggini, M.N.Weedon, C.M.Lindgren, T.M.Frayling, K.S.Elliott, H.Lango, N.J.Timpson, J.R.Perry, N.W.Rayner, R.M.Freathy, J.C.Barrett, B.Shields, A.P.Morris, S.Ellard, C.J.Groves, L.W.Harries, J.L.Marchini, K.R.Owen, B.Knight, L.R.Cardon, M.Walker, G.A.Hitman, A.D.Morris, A.S.Doney, M.I.McCarthy, A.T.Hattersley. Replication of genome-wide association signals in UK samples reveals risk loci for type 2 diabetes, Science, 316, (2007) 1336-1341.

[8] P.J.Talmud, A.D.Hingorani, J.A.Cooper, M.G.Marmot, E.J.Brunner, M.Kumari, M.Kivimaki, S.E.Humphries. Utility of genetic and non-genetic risk factors in prediction of type 2 diabetes: Whitehall II prospective cohort study, BMJ, 340, (2010) b4838.

[9] J.Hebebrand, A.L.Volckmar, N.Knoll, A.Hinney. Chipping away the 'missing heritability': GIANT steps forward in the molecular elucidation of obesity - but still lots to go, Obes.Facts., 3, (2010) 294-303.

[10] S.R.Colberg, J.A.Simoneau, F.L.Thaete, D.E.Kelley. Skeletal muscle utilization of free fatty acids in women with visceral obesity, J.Clin.Invest, 95, (1995) 1846-1853.

[11] E.E.Blaak. Fatty acid metabolism in obesity and type 2 diabetes mellitus, Proc.Nutr.Soc., 62, (2003) 753-760.

[12] D.E.Kelley, J.A.Simoneau. Impaired free fatty acid utilization by skeletal muscle in noninsulin-dependent diabetes mellitus, J.Clin.Invest, 94, (1994) 2349-2356.

[13] J.A.Simoneau, J.H.Veerkamp, L.P.Turcotte, D.E.Kelley. Markers of capacity to utilize fatty acids in human skeletal muscle: relation to insulin resistance and obesity and effects of weight loss, FASEB J., 13, (1999) 2051-2060.

[14] L.Abu-Elheiga, M.M.Matzuk, K.A.Abo-Hashema, S.J.Wakil. Continuous fatty acid oxidation and reduced fat storage in mice lacking acetyl-CoA carboxylase 2, Science, 291, (2001) 2613-2616.

[15] L.Abu-Elheiga, W.R.Brinkley, L.Zhong, S.S.Chirala, G.Woldegiorgis, S.J.Wakil. The subcellular localization of acetyl-CoA carboxylase 2, Proc.Natl.Acad.Sci.U.S.A, 97, (2000) 1444-1449.

[16] J.L.Hernandez, J.M.Olmos, E.Pariente, J.Martinez, C.Valero, P.Garcia-Velasco, D.Nan, J.Llorca, J.Gonzalez-Macias. Metabolic syndrome and bone metabolism: the Camargo Cohort Study, Menopause, 17, (2010) 955-961.

[17] J.A.Riancho, J.M.Olmos, B.Pineda, C.Garcia-Ibarbia, M.I.Perez-Nunez, D.N.Nan, J.Velasco, A.Cano, M.A.Garcia-Perez, M.T.Zarrabeitia, J.Gonzalez-Macias. Wnt receptors, bone mass, and fractures: gene-wide association analysis of LRP5 and LRP6 polymorphisms with replication, Eur.J Endocrinol, 164, (2011) 123-131. 
[18] F.Renstrom, F.Payne, A.Nordstrom, E.C.Brito, O.Rolandsson, G.Hallmans, I.Barroso, P.Nordstrom, P.W.Franks. Replication and extension of genome-wide association study results for obesity in 4923 adults from northern Sweden, Hum.Mol.Genet., 18, (2009) 14891496.

[19] S.Genuth, K.G.Alberti, P.Bennett, J.Buse, R.Defronzo, R.Kahn, J.Kitzmiller, W.C.Knowler, H.Lebovitz, A.Lernmark, D.Nathan, J.Palmer, R.Rizza, C.Saudek, J.Shaw, M.Steffes, M.Stern, J.Tuomilehto, P.Zimmet. Follow-up report on the diagnosis of diabetes mellitus, Diabetes Care, 26, (2003) 3160-3167.

[20] K.Quandt, K.Frech, H.Karas, E.Wingender, T.Werner. MatInd and MatInspector: new fast and versatile tools for detection of consensus matches in nucleotide sequence data, Nucleic Acids Res., 23, (1995) 4878-4884.

[21] V.D.Marinescu, I.S.Kohane, A.Riva. MAPPER: a search engine for the computational identification of putative transcription factor binding sites in multiple genomes, BMC.Bioinformatics., 6, (2005) 79.

[22] P.Mozas, R.Galetto, M.Albajar, E.Ros, M.Pocovi, J.C.Rodriguez-Rey. A mutation (-49C>T) in the promoter of the low density lipoprotein receptor gene associated with familial hypercholesterolemia, Journal of Lipid Research, 43, (2002) 13-18.

[23] K.Alheim, J.Corness, M.K.Samuelsson, L.G.Bladh, T.Murata, T.Nilsson, S.Okret. Identification of a functional glucocorticoid response element in the promoter of the cyclindependent kinase inhibitor p57Kip2, J.Mol.Endocrinol., 30, (2003) 359-368.

[24] H.A.Ely, P.L.Mellon, D.Coss. GnRH induces the c-Fos gene via phosphorylation of SRF by the calcium/calmodulin kinase II pathway, Mol.Endocrinol., 25, (2011) 669-680.

[25] J.C.Barrett, B.Fry, J.Maller, M.J.Daly. Haploview: analysis and visualization of LD and haplotype maps, Bioinformatics, 21, (2005) 263-265.

[26] S.Purcell, B.Neale, K.Todd-Brown, L.Thomas, M.A.Ferreira, D.Bender, J.Maller, P.Sklar, P.I.de Bakker, M.J.Daly, P.C.Sham. PLINK: a tool set for whole-genome association and population-based linkage analyses, Am.J.Human Genet., 81, (2007) 559-575.

[27] D.R.Nyholt. A simple correction for multiple testing for single-nucleotide polymorphisms in linkage disequilibrium with each other, Am.J.Human Genet., 74, (2004) 765-769.

[28] C.S.Choi, D.B.Savage, L.Abu-Elheiga, Z.X.Liu, S.Kim, A.Kulkarni, A.Distefano, Y.J.Hwang, R.M.Reznick, R.Codella, D.Zhang, G.W.Cline, S.J.Wakil, G.I.Shulman. Continuous fat oxidation in acetyl-CoA carboxylase 2 knockout mice increases total energy expenditure, reduces fat mass, and improves insulin sensitivity, Proc.Natl.Acad.Sci U.S.A, 104, (2007) 16480-16485.

[29] D.P.Olson, T.Pulinilkunnil, G.W.Cline, G.I.Shulman, B.B.Lowell. Gene knockout of Acc2 has little effect on body weight, fat mass, or food intake, Proc.Natl.Acad.Sci.U.S.A, 107, (2010) 7598-7603.

[30] d.E.Szabo, L.Goumidi, S.Bertrais, C.Phillips, R.Macmanus, H.Roche, R.Planells, D.Lairon. Prediction of the metabolic syndrome status based on dietary and genetic parameters, using Random Forest, Genes Nutr., 3, (2008) 173-176. 
[31] S.Maeda, M.A.Kobayashi, S.Araki, T.Babazono, B.I.Freedman, M.A.Bostrom, J.N.Cooke, M.Toyoda, T.Umezono, L.Tarnow, T.Hansen, P.Gaede, A.Jorsal, D.P.Ng, M.Ikeda, T.Yanagimoto, T.Tsunoda, H.Unoki, K.Kawai, M.Imanishi, D.Suzuki, H.D.Shin, K.S.Park, A.Kashiwagi, Y.Iwamoto, K.Kaku, R.Kawamori, H.H.Parving, D.W.Bowden, O.Pedersen, Y.Nakamura. A single nucleotide polymorphism within the acetyl-coenzyme A carboxylase beta gene is associated with proteinuria in patients with type 2 diabetes, PLoS.Genet., 6, (2010) e1000842.

[32] S.C.Tang, V.T.Leung, L.Y.Chan, S.S.Wong, D.W.Chu, J.C.Leung, Y.W.Ho, K.N.Lai, L.Ma, S.C.Elbein, D.W.Bowden, P.J.Hicks, M.E.Comeau, C.D.Langefeld, B.I.Freedman. The acetyl-coenzyme A carboxylase beta (ACACB) gene is associated with nephropathy in Chinese patients with type 2 diabetes, Nephrol.Dial.Transplant., 25, (2010) 3931-3934.

[33] S.Li, J.H.Zhao, J.Luan, R.N.Luben, S.A.Rodwell, K.T.Khaw, K.K.Ong, N.J.Wareham, R.J.Loos. Cumulative effects and predictive value of common obesity-susceptibility variants identified by genome-wide association studies, Am.J Clin Nutr., 91, (2010) 184-190.

[34] M.R.Wing, J.M.Ziegler, C.D.Langefeld, B.H.Roh, N.D.Palmer, E.J.Mayer-Davis, M.J.Rewers, S.M.Haffner, L.E.Wagenknecht, D.W.Bowden. Analysis of FTO gene variants with obesity and glucose homeostasis measures in the multiethnic Insulin Resistance Atherosclerosis Study cohort, Int J Obes.(Lond), (2010).

[35] T.M.Frayling, N.J.Timpson, M.N.Weedon, E.Zeggini, R.M.Freathy, C.M.Lindgren, J.R.Perry, K.S.Elliott, H.Lango, N.W.Rayner, B.Shields, L.W.Harries, J.C.Barrett, S.Ellard, C.J.Groves, B.Knight, A.M.Patch, A.R.Ness, S.Ebrahim, D.A.Lawlor, S.M.Ring, Y.Ben Shlomo, M.R.Jarvelin, U.Sovio, A.J.Bennett, D.Melzer, L.Ferrucci, R.J.Loos, I.Barroso, N.J.Wareham, F.Karpe, K.R.Owen, L.R.Cardon, M.Walker, G.A.Hitman, C.N.Palmer, A.S.Doney, A.D.Morris, G.D.Smith, A.T.Hattersley, M.I.McCarthy. A common variant in the FTO gene is associated with body mass index and predisposes to childhood and adult obesity, Science, 316, (2007) 889-894.

[36] P.Froguel, A.I.Blakemore. The power of the extreme in elucidating obesity, N.Engl.J.Med., 359, (2008) 891-893.

[37] C.M.Phillips, L.Goumidi, S.Bertrais, M.R.Field, L.A.Cupples, J.M.Ordovas, J.McMonagle, C.Defoort, J.A.Lovegrove, C.A.Drevon, E.E.Blaak, B.Kiec-Wilk, U.Riserus, J.LopezMiranda, R.McManus, S.Hercberg, D.Lairon, R.Planells, H.M.Roche. ACC2 gene polymorphisms, metabolic syndrome, and gene-nutrient interactions with dietary fat, J Lipid Res, 51, (2010) 3500-3507.

[38] W.Jin, A.B.Goldfine, T.Boes, R.R.Henry, T.P.Ciaraldi, E.Y.Kim, M.Emecan, C.Fitzpatrick, A.Sen, A.Shah, E.Mun, V.Vokes, J.Schroeder, E.Tatro, J.Jimenez-Chillaron, M.E.Patti. Increased SRF transcriptional activity in human and mouse skeletal muscle is a signature of insulin resistance, J.Clin.Invest, 121, (2011) 918-929. 